\title{
Нитевидные светодиодные микрокристаллы InGaN/GaN субмиллиметровой длины
}

\author{
(C) В.В. Лундин ${ }^{1}$, С.Н. Родин ${ }^{1}$, А.В. Сахаров ${ }^{1}$, Е.Ю. Лундина ${ }^{1}$, С.О. Усов ${ }^{2}$, \\ Ю.М. Задиранов ${ }^{1}$, С.И. Трошков ${ }^{1}$, А.Ф. Цацульников ${ }^{2,3}$ \\ ${ }^{1}$ Физико-технический институт им. А.Ф. Иоффе Российской академии наук, \\ 194021 Санкт-Петербург, Россия \\ ${ }^{2}$ Научно-технологический центр микроэлектроники \\ и субмикронных гетероструктур Российской академии наук, \\ 194021 Санкт-Петербург, Россия \\ ${ }^{3}$ Санкт-Петербургский национальный исследовательский университет \\ информационных технологий, механики и оптики, \\ 197101 Санкт-Петербург, Россия \\ E-mail: lundin.vpegroup@mail.ioffe.ru
}

(Получена 25 апреля 2016 г. Принята к печати 29 апреля 2016 г.)

Нитевидные микрокристаллические светодиодные структуры InGaN/GaN в коаксиальной геометрии длиной 400-600 мкм были выращены методом газофазной эпитаксии из металлоорганических соединений на сапфировых и кремниевых подложках. Использовалась технология сверхбыстрого роста нитевидных нано- и микрокристаллов, индуцированного нанослоем титана. При протекании тока наблюдалась электролюминесценция микрокристаллов в сине-зеленом спектральном диапазоне.

DOI: 10.21883/FTP.2017.01.44003.8293

\section{1. Введение}

Структуры на основе нитевидных нано- и микрокристаллов (ННК и НМК) III-N в последние годы привлекают существенное внимание исследователей из-за ряда потенциальных преимуществ. В таких структурах практически отсутствуют механические напряжения, вызванные рассогласованием параметров кристаллической решетки и коэффициентов теплового расширения между подложкой и эпитаксиальными слоями. На основе ННК и НМК возможно создание акселерометров и других устройств наномеханики. Светодиодные структуры на основе ННК и НМК, в которых активная область и слои $p$-типа проводимости расположены на боковых поверхностях (коаксиальная геометрия, core-shell), при той же площади приборного кристалла, могут иметь намного большую площадь $p-n$-перехода, чем традиционные планарные гетероструктуры, что снижает проблему падения эффективности люминесценции с возрастанием плотности тока. Также такие структуры привлекательны для создания различного рода сенсоров, чувствительных к составу окружающей среды за счет большей площади поверхности.

Традиционные методы формирования ННК и НМК основаны на использовании металлических катализаторов $[1,2]$, селективной эпитаксии $[3,4]$ или самоорганизации за счет упругих напряжений $[5,6]$. В последнее время в нашей лаборатории развивается технология роста НMK GaN, индуцированных нанослоем титана $[7,8]$. Показано, что эта технология позволяет достичь рекордных скоростей роста ( 800 мкм/ч) при сохранении высокого качества материала и выращивать структуры с НMК GaN длиной в сотни микрометров при малой продолжительности эпитаксиального процесса. В на- стоящей работе мы показываем возможность создания светодиодных структур на основе этой технологии.

\section{2. Формирование нитевидных микрокристаллов InGaN/GaN}

Эпитаксиальные структуры с НМК формировались методом газофазной эпитаксии из металлоорганических соединений (MOVPE) в модернизированной установке Epiquip VP50RP c индукционно нагреваемым горизонтальным реактором. Триметилгаллий, триметилиндий, аммиак, моносилан, бисциклопентадиенил магния $\left(\mathrm{Cp}_{2} \mathrm{Mg}\right)$, водород и азот использовались в качестве соединений-источников и несущих газов. Выращивание НМК производилось на поверхности слоя титана, нанесенного термическим или магнетронным распылением на сапфировые подложки ориентации (0001) или эпитаксиальные слои AlN ориентации (0001), выращенные методом MOVPE на кремниевых подложках ориентации (111).

Первый этап формирования НМК проводился аналогично ранее описанному [8], при низкой концентрации аммиака в атмосфере реактора, что приводило к доминированию вертикальной компоненты роста. Непринципиальное отличие от режимов выращивания, описанных в работе [8], состояло во введении в реактор моносилана для получения НМК $n$-типа проводимости. Кроме того, была произведена дополнительная, более тонкая оптимизация толщины титановой пленки. Установлено, что при ее толщине в диапазоне 10-20 нм НМК формируются в широком диапазоне условий в реакторе. При уменьшении толщины титановой пленки до 6-8нм диапазон допустимых условий в реакторе 

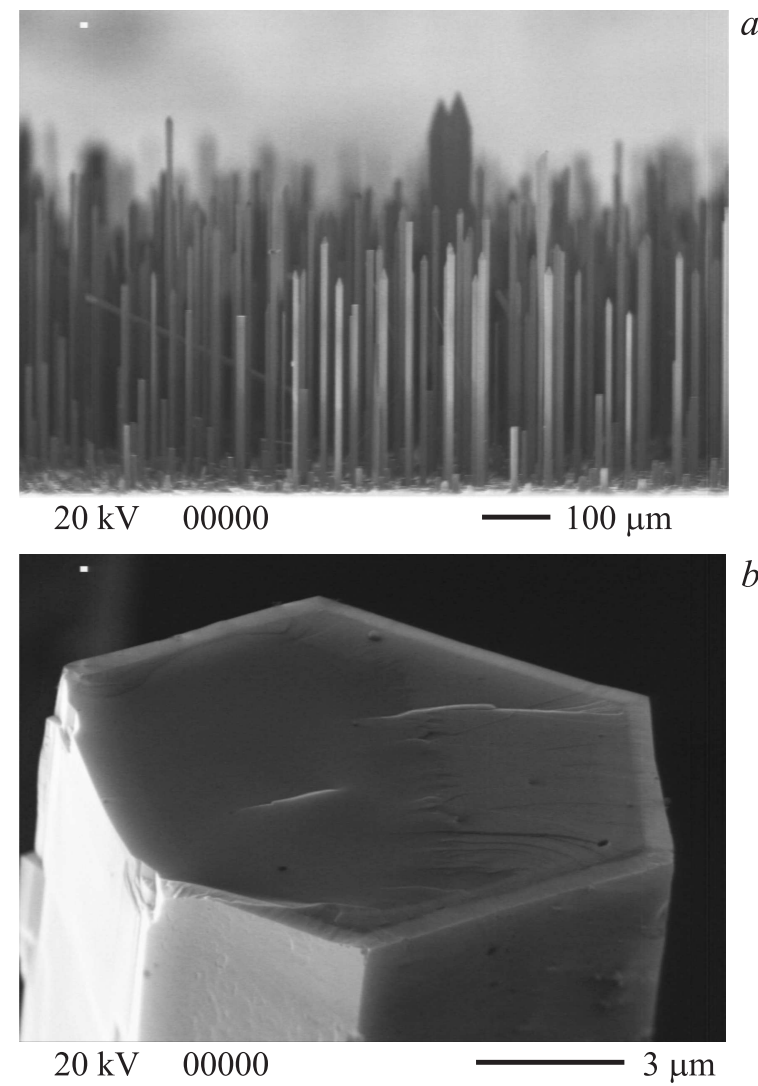

Рис. 1. РЭМ-фотографии светодиодных НМК $\mathrm{InGaN} / \mathrm{GaN}$ : общий вид $(a)$ и поперечный скол на середине высоты $(b)$. Светлый внешний слой $-p-\mathrm{GaN}$.

сужается, однако одновременно уменьшается дисперсия НМК по длине, в основном за счет исчезновения редких НМК с самой большой длиной. При дальнейшем уменьшении толщины титановой пленки мы не наблюдали формирования НМК. Возможно, для таких очень тонких титановых пленок необходимый диапазон условий в реакторе узок и пока что еще не найден.

Длительность этапа вертикального роста в данной работе по сравнению с [8] была увеличена с целью формирования массива НМК с доминирующей длиной 400-600 мкм для упрощения их последующего исследования. Было замечено, что при этом, помимо типичных для данного метода кристаллитов диаметром единицы микрометров, формировались отдельные редкие кристаллиты несколько увеличенной длины булавовидной формы, с диаметром, возрастающим в верхней части до 20-40 мкм. Подробно они в данной работе не исследовались. Предположительно, они формируются на заключительной части данного этапа роста из обычных НМК наибольшей длины, верхние концы которых находятся в слое газа с большей концентрацией прекурсоров, в результате нарушения баланса притока галлия и азота к поверхности растущего кристаллита.

После достижения НМК $n$-GaN длины 400-500 мкм условия в реакторе изменялись, и выращивание актив- ной области на основе нескольких квантовых ям InGaN, разделенных барьерами $\mathrm{GaN}$, и слоя $p$-GaN производилось в режимах, оптимизированных для эпитаксии планарных светодиодов InGaN/GaN при высокой концентрации аммиака, что значительно увеличивало скорость роста в боковом направлении. Поэтому активная область и слой $p$ - $\mathrm{GaN}$ формировались на всей боковой поверхности НМК, т. е. реализовывалась коаксиальная геометрия светодиодной структуры НМК. Полученное в растровом электронном микроскопе (РЭМ) изображение массива НМК приведено на рис. 1, $a$. На заднем плане видны два вышеупомянутых булавовидных кристаллита.

На части структур с НМК методом термического распыления под острым углом к подложке наносились металлические контакты Ni/Au различной толщины. Предполагалось, что из-за высокой плотности расположения НМК на подложке благодаря затенению металлические контакты будут формироваться только на верхней части боковой стенки наиболее высоких НМК.

\section{3. Методы и результаты исследования нитевидных микрокристаллов InGaN/GaN}

Выращенные структуры исследовались с помощью оптической и растровой электронной микроскопии. Спектры микрофотолюминесценции регистрировались при возбуждении Не-Cd-лазером (длина волны излучения $\lambda=325$ нм) на установке на основе люминесцентного микроскопа Люмам. Для этих исследований НМК механически отделялись от подложки и помещались на объектодержатель микроскопа.

Изучение электролюминесцентных свойств выращенных НМК осуществлялось без их отделения от подложки, при этом поликристаллический слой $\mathrm{GaN}$, покрывающий поверхность подложки между НМК, выступал в качестве $n$-контактного слоя. Положительное смещение подавалось через металлический зонд, подводимый к боковой поверхности отдельного НМК. В распространенных стандартных микрозондовых установках на основе оптических микроскопов зонды опускаются на контактные площадки исследуемых объектов сверху. В нашем случае из-за малых размеров НМК это привело бы к их существенному затенению зондом. Поэтому для описываемых в данной работе исследований была собрана специальная установка на основе оптического микроскопа (МКД-Р, ЛОМО), трехкоординатного микроманипулятора с контактным зондом и соединенной с компьютером видеокамеры, которая позволяла подводить зонд к исследуемому НМК снизу. Подложка располагалась параллельно, а НМК - перпендикулярно оптической оси микроскопа. Схема эксперимента показана на рис. 2, $a$.

С помощью этой же установки готовились поперечные сколы НМК для РЭМ-исследований. Установлено, что при приложении к НМК усилия поперек оси они 

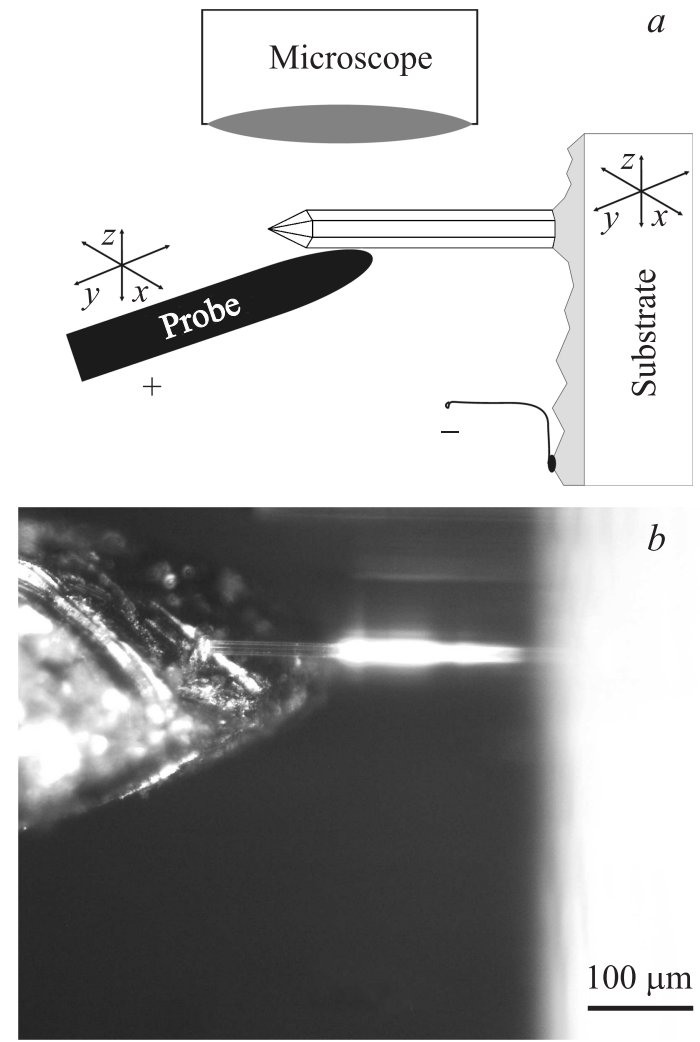

Рис. 2. Схема подведения зонда для исследования электролюминесценции НМК $(a)$ и оптическая микрофотография электролюминесценции НMК $\mathrm{InGaN} / \mathrm{GaN}(b) . b$ - подложка справа (не в фокусе).

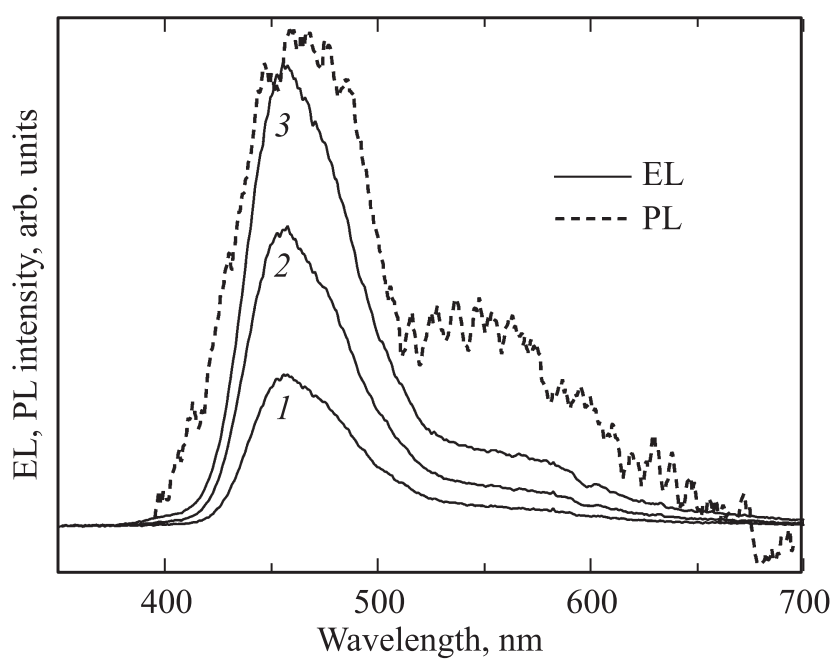

Pис. 3. Спектры фото- (PL) и электролюминесценции (EL) светодиодного НМК InGaN/GaN. Ток через НМК, мкА: $1-100,2-200,3-500$.

практически всегда отделяются от подложки вблизи основания, а такие сколы не показательны. Поэтому скалывание НМК осуществлялось при давлении зондом вдоль его оси, что приводило к изгибу и последующему раскалыванию НМК в его средней части. РЭМ-фотография во вторичных электронах поперечного скола НМК приведена на рис. $1, b$. Отчетливо видно, что слой $p$-GaN, имеющий более светлый тон, охватывает НМК по периметру. Изучение спектров микрофотолюминесценции, снятых с различных точек вдоль НМК, показало, что активная область InGaN/GaN формировалась по всей их длине. Тем самым можно считать доказанной формирование НМК $\mathrm{InGaN} / \mathrm{GaN}$ с $p-n$-переходом в коаксиальной геометрии Микрофотография НМК при протекании тока приведена на рис. 2, $b$. На рис. 3 приведены спектры фото- и электролюминесценции НМК, на различных кристаллитах наблюдается люминесценция на разных длинах волн в сине-зеленом спектральном диапазоне. Несмотря на крайне малую величину тока, электролюминесценция НМК была отчетливо видна в освещенной комнате. Характер вывода света определялся в основном волноводными эффектами и мало зависел от точного положения точки касания зонда поверхности НМК. Установлено, что для НМК, на боковые стенки которых напылены тонкие металлические контакты $\mathrm{Ni}-\mathrm{Au}$ (номинально, согласно калибровочным процессам напыления на плоские поверхности, суммарная толщина металла составляла 10 нм), характерны меньшие напряжения отсечки $(\sim 3 \mathrm{~B})$ и меньшее дифференциальное сопротивление ( $\sim 50$ кОм), чем для НМК без металлических контактов. При большей толщине напыленных контактных слоев наблюдалась вольт-амперная характеристика омического типа. По-видимому, переосаждение металла при напылении приводило к формированию шунтирующих металлических мостиков между $p$-GaN и поликристаллическим слоем $n-\mathrm{GaN}$ вблизи основания НМК. Наблюдавшиеся величины дифференциального сопротивления НМК находятся в хорошем соответствии с ожидавшимися значениями для $\mathrm{GaN}$, легированного кремнием.

Свойства светодиодных НMК InGaN/GaN, выращенных на сапфировых подложках и на $\mathrm{AlN} / \mathrm{Si}$ были близки. Какой-либо существенной разницы между структурами, выращенными на титановых пленках, сформированных термическим и магнетронным напылением, не выявлено. Электролюминесценция булавовидных кристаллитов была аналогична электролюминесценции типичных для данной работы НМК.

\section{4. Заключение}

В результате проведенных исследований подтверждена применимость ранее разработанной технологии сверхбыстрого выращивания HМK GaN, индуцированного нанослоем титана, для формирования светодиодных структур. Созданы и исследованы НМК-светодиоды видимого диапазона с длиной кристаллитов 300-500 мкм и диаметром 5-15 мкм, показана возможность получения излучения от отдельного НМК. 


\section{Список литературы}

[1] J.-P. Ahl, H. Behmenburg, C. Giesen, I. Regolin, W. Prost, F.J. Tegude, G.Z. Radnoczi, B. Pécz, H. Kalisch, R.H. Jansen, M. Heuken. Phys. Status Solidi C, 8 (7-8), 2315 (2011).

[2] Q. Li, G.T. Wang. Appl. Phys. Lett., 93, 043119 (2008).

[3] S.D. Hersee, X. Sun, X. Wang. Nano Lett., 6, 808 (2006).

[4] T. Schumann, T. Gotschke, F. Limbach, T. Stoica, R. Calarco. Nanotechnology, 22 (9), 095603 (2011).

[5] M.A. Sanchez-Garcia, E. Calleja, E. Monroy, F.J. Sanchez, F. Calle, E. Munoz, R. Beresford. J. Cryst. Growth, 183 (1-2), 23 (1998).

[6] V. Consonni, V.G. Dubrovskii, A. Trampert, L. Geelhaar, H. Riechert. Phys. Rev. B, 85, 155313 (2012).

[7] М.М. Рожавская, В.В. Лундин, Е.Ю. Лундина, А.В. Сахаров, С.И. Трошков, А.Н. Смирнов, В.Ю. Давыдов. Письма ЖТФ, 40 (9), 17 (2014).

[8] M.M. Rozhavskaya, W.V. Lundin, E.Yu. Lundina, V.Yu. Davydov, S.I. Troshkov, A.A. Vasilyev, P.N. Brunkov, A.V. Baklanov, A.F. Tsatsulnikov, V.G. Dubrovskii. J. Appl. Phys., 117, 024301 (2015).

Редактор Л.В. Шаронова

\section{InGaN/GaN micro-wire light-emitting diodes of sub-millimeter length}

W.V. Lundin'1, S.N. Rodin'1, A.V. Sakharov' ${ }^{1}$, E.Yu. Lundina ${ }^{1}$, S.O. Usov' ${ }^{2}$, Yu.M. Zadiranov ${ }^{1}$, S.I. Troshkov' ${ }^{1}$, A.F. Tsatsulnikov ${ }^{2,3}$

${ }^{1}$ loffe Institute, 194021 St. Petersburg, Russia

${ }^{2}$ Submicron Heterostructures for Microelectronics,

Research \& Engineering Center,

Russian Academy of Sciences, 194021 St. Petersburg, Russia

${ }^{3}$ Saint Petersburg National Research University of Information Technologies, Mechanics and Optics, 197101 St. Petersburg, Russia

Abstract InGaN/GaN micro-wire light-emitting diodes in coreshell geometry of $400-600 \mu \mathrm{m}$ length were grown by metallorganic vapor phase epitaxy on sapphire and silicon substrates. Technique of extra-fast growth induced by titanium nano-film was used. Microcrystals demonstrated electroluminescence in bluegreen spectral range. 